\title{
GOLIATH FALLS
}

\author{
Identity crisis.
}

\section{BY TAIK HOBSON}

$\mathrm{I}^{\mathrm{n}}$ 'm tucked so far up Shifu's axila that - right before his arm completes its arc - my olfactory sensors experience overload.

SLAM

"Who are you?"

Contact with the floor happens in optimal hand-forearm-shoulder blade-flank sequence, while Shifu's question - the same one for the past two months - arrives somewhere in there like a distant echo. Rolling to my side, I get to my feet, right servo aimed at the forehead of the man in the white robe across from me. Saturation can't be too far off now, I think, right before I rush him and, like a closed circuit, the sequence repeats itself. Evasion. Engagement (re: olfactory alert) and Execution.

SLAM

Physical analysis of Shifu's Execution concludes an improbable amount of force; it just isn't possible for his body to manoeuvre that amount of energy sans joint augmentation. And yet every time, I end up on the ground. From what I have seen, skill level tends towards a certain personality type; the one that Shifu happens to be demonstrating is No Ego.

"Who are you?"

For me, he is my last hope - SLAM no one else will train with me - SLAM - I do not know why he puts himself in harm's way - SLAM - the only explanation he has given me - SLAM - is this: that I am running out of time.

"Who are you?"

Shifu is, of course, referring to the time I have left to attain my upgrade; unless I achieve some higher level of understanding - and do so soon - I will have to enrol in a new, entirely different programme.

But I came here to learn Kung Fu.

There was a time when upgrades happened as a matter of course, withheld - if ever - by nothing more than a simple password; now the Diversity Dictum would see each unit further their pursuit of individuality and self-expression through subjective, real-time experiences. I am the first student to enrol in the Qi programme; a non-verbal combat narrative, and new to the Diversity Curriculum, its future
Follow Futures:

@ @ NatureFutures

f go.nature.com/mtoodm

\section{NATURE.CON}

inclusion hinges upon my success. A teacher, I have learnt, must have his students.

"Their spines will regrow," I have been assured, although the two absent members from the training hall are muted reminders of how far things can go.

Tumbling Goliath is the first technique by which each student may demonstrate Kung

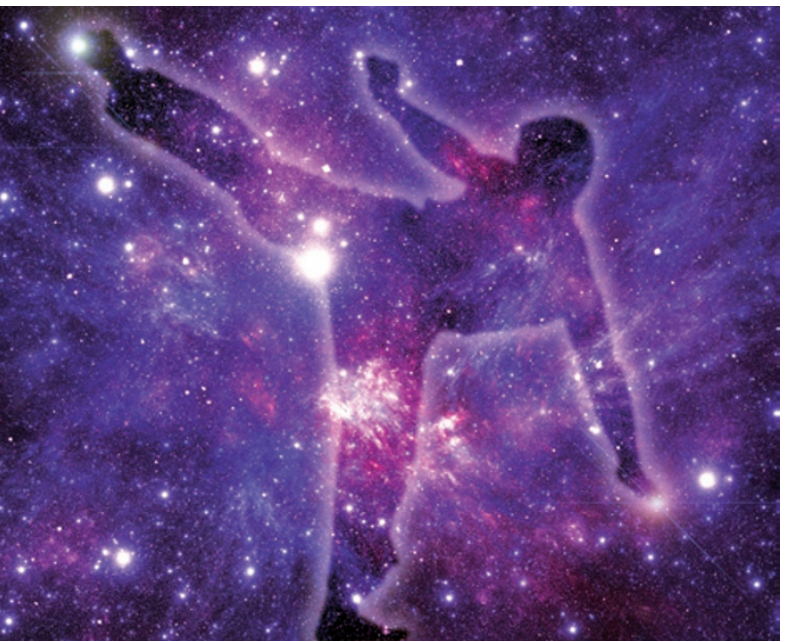

Fu competency; with the passing of the Founder it remains a strictly implemented requirement, despite the steep drop in enrolment. It is composed of three separate movements and all students start by practising with a partner.

"Who are you?"

As part of the Qi programme, I have unlimited access into my own memories. Free to review and reenact my lessons, importantly, I am allowed to remove all that is unnecessary from my practice; in itself perhaps the hardest lesson of all.

\section{SLAM}

The first thing I erased was my name.

Like everything else, Kung Fu exists within the bounds of information; each time I fall, motion sensors collate the data to form the parameter whereby I may tease apart Shifu's technique. Yet with each parametric saturation - when I am allowed a glimpse into what it is I must learn - I feel that I am drifting farther and farther away from my goal. Meanwhile, the findings are unchanged: just not possible.

Now it is Shifu's turn to attack me; it is my turn to receive and I am afraid to hurt this man with No Ego. Even as I Engage I know that my Execution will be unsatisfactory so I do it as gently as I can. Crawling to his feet, Shifu doesn't bother to hide his disappointment.

Who am I?

I recall my meeting with the Founder, long before I was enrolled. I do not have the soundbite, but I remember what he said. "That you are a machine is not a problem." Shifu starts to speak, but the Founder's words are all I hear. "That you think to act like a man - that is a problem." I AM NOTHING.

I have not heard my voice for so long that I can barely recognize the sound of it. Analysis Status flashes: SATURATION, when Shifu starts coming at me.

I know that this is the end; perhaps I should have chosen a less abstract programme ... the Ramsay Culinary Kitchen, for instance. Now, even as I move into position, one by one I feel my tension points break with resignation. I. Am. Nothing.

Evasion. Engagement -

Shifu rolls to a stand but doesn't say a word; from what I can see, nothing looks broken. No time to analyse; here he comes again. When next I Execute I am neither restrained nor resigned; instead, I let his body travel the length of its intended attack, before guiding him into his fall. Unlike every other archived entry, in these last two attempts it is as though I am doing nothing at all.

And then I know who I am. I know how Shifu does what he does without joint augmentation. And I know where the force comes from.

SLAM

I am neither machine nor man; 'I' am an extension of matter. And my movements, just like Shifu's, are momentarily in sync with the physical properties of the Universe.

Gravity, for example.

All the attention in the training hall is directed at the two of us. Shifu, I can see, is smiling beneath a headful of sweat. Of course, I had to know, so I asked him.

NOW WHAT?

"Now?" Readjusting his robe, Shifu nods to one of his students, who in turn starts for a corner of the hall, where two tall panels of solid iron sit shut behind a vaulted lock.

"Release the Goliath."
Taik Hobson lives in Japan, where he remains well acquainted with the floor of his dojo. 